\title{
Single Nucleotide Polymorphism Genotyping Using Allele-Specific PCR and Fluorescence Melting Curves
}

BioTechniques 34:1068-1072 (May 2003)

Audrey C. Papp, Julia K. Pinsonneault, Glen Cooke, and Wolfgang Sadée Ohio State University, Columbus, OH, USA

\section{ABSTRACT}

We present a PCR method for identification of single nucleotide polymorphisms $(S N P S)$, using allele-specific primers designed for selective amplification of each allele. Matching the SNP at the 3' end of the forward or reverse primer, and additionally incorporating a 3' mismatch to prevent amplification of the incorrect allele, results in selectivity of the allele-specific primers. DNA melting analysis with fluorescent $S Y B R^{\circledR}$ Green affords detection of the PCR products. By incorporating a GC-rich sequence into one of the two allele-specific primers to increase the melting temperature, both alleles can be measured simultaneously at their respective melting temperatures. Applying the DNA melting analysis to SNPs in $\mathrm{ApoE}$ and $\mathrm{ABCA} 1$ yielded results identical to those obtained with other genotyping methods. This provides a cost-effective, high-throughput method for amplification and scoring of SNPS.

\section{INTRODUCTION}

Genetic differences between individuals are thought to confer susceptibility to disease (1) and determine response to therapy (2). As a result of the human genome project, the need for rapid inexpensive methods for DNA genotyping is growing exponentially $(3,4)$. Here we describe a one-well method for identification of single nucleotide polymorphisms (SNPs), including alleles differing by a single base change.

A standard genotyping assay involves PCR amplification followed by restriction enzyme digestion. However, restriction enzyme digestion requires an informative site and a multistep process, including PCR, digestion, electrophoresis, fragment staining, and image capture. Multiple alternative techniques have emerged, including differential hybridization methods such as allelespecific oligonucleotide hybridization (5) and fluorescent probes (6); melting temperature-based separation including single-stranded conformational polymorphism (SSCP) (7), heteroduplex analysis (8), and DHPLC (9); allelespecific amplification (10); and DNA sequencing (11) or primer extension (12) to distinguish SNP alleles.

The above procedures rely on initial PCR amplification with subsequent analytical steps. Recently, PCR and detection have been integrated into one process. Rapid allele discrimination by PCR using allele-specific TaqMan ${ }^{\circledR}$ probes permits analysis of both alleles simultaneously (13). The quenched fluorescent tags of the probes are cleaved during PCR amplification by the $5^{\prime}$ exonuclease activity inherent to the Taq DNA polymerase used. For optimal allele discrimination, the probes are used with a two-dye reporter system and a reference dye. The cost of these probes can be considerable. As with most systems, the cost per assay declines as the volume increases, but the start-up cost can be quite high, in particular if numerous different SNPs are to be measured.

Fluorescence melting curve analysis using a standard dye (SYBR ${ }^{\circledR}$ Green) (14) can provide single-tube amplification and detection of polymorphic alleles, if the melting temperatures of the two alleles are sufficiently different. An alternative approach employs allelespecific PCR (15), which can be used with SYBR Green. The allele-specific primer matches at its $3^{\prime}$ end either of the two alleles. Introducing an additional primer mismatch serves to enhance discrimination between the two alleles (16). The allele-specific reactions must be performed in separate wells, with nonspecific fluorescent labeling and detection. However, this requires two reactions for each assay, doubling the amount of reagent and DNA expended. To avoid this, we introduce a 10- to 15 bp GC clamp (17) onto the $5^{\prime}$ end of one of the two allele-specific primers, thereby introducing a difference in melting temperature between the two allelic PCR products. The resulting melting curves are significantly different. Following 30-40 cycles of PCR, fluorescence melting curve analysis (i.e., release of SYBR Green from double-stranded products) permits complete discrimination between the two alleles in the same reaction well. 
We analyzed SNPs in the genes encoding apolipoprotein $\mathrm{E}(A p o E)$ and the cholesterol efflux pump, ATP binding cassette $\mathrm{A} 1(A B C A 1)$, as part of an ongoing pharmacogenomic investigation of coronary artery disease. ApoE is one of many candidate genes implicated in cardiovascular and neurological disorders and in response to drug therapy (18). ApoE plays a significant role in cholesterol metabolism, including transport and clearance of circulating low-density lipoprotein (LDL) and very low-density lipoprotein (VLDL) cholesterol. There are three well-characterized variants of $A p o E, \varepsilon 2, \varepsilon 3$, and $\varepsilon 4$, which differ by their specific combination of nonsynonymous base changes at two positions: codon 112, or codon 158 ( $\varepsilon 2$ has cysteine at both codon 112 and $158, \varepsilon 3$ has cysteine at 112 and arginine at 158 , and $\varepsilon 4$ has arginine at both 112 and 158) (19). These amino acid changes cause differences in the ApoE lipid and receptor binding characteristics. The ApoE $\varepsilon 3$ allele is the most prevalent genotype in the human population today, having an allele frequency of $60 \%-90 \%$. ApoE $\varepsilon 4$ is thought to be the ancestral allele, with a relative frequency of $5 \%-41 \%(20)$.

$A B C A 1$ facilitates reverse cholesterol transport (21). A nonsynonymous G-to-A transition causes an amino acid change from arginine $(\mathrm{R})$ to lysine $(\mathrm{K})$ at codon 219 . $A B C A 1 \mathrm{R} 219 \mathrm{~K}$ is a relatively common polymorphism, with an incidence of $46 \%$ in the European population (22). The K variant has been reported to be associated with increased levels of high-density lipoprotein (HDL) and reduced coronary artery disease (23). Allelic variants of these two genes are included with this study to illustrate the performance of the assay over a range of GC content surrounding the SNP.

\section{MATERIALS AND METHODS}

\section{Instrumentation}

An ABI 7000 instrument (Applied Biosystems, Foster City, CA, USA) was used for PCR amplification and fluorescence melting curve analysis. The PCR volume was $25 \mu \mathrm{L}$. PCR was performed in standard 96-well plates, sealed with optical adhesive covers After amplification, the fluorescence intensity of the PCR product was measured from $60^{\circ} \mathrm{C}$ to $92^{\circ} \mathrm{C}$ at a temperature gradient of $0.2^{\circ} \mathrm{C} / \mathrm{min}$. The ABI 7000 automatically calculates the negative derivative of the change in fluorescence. When graphed, this yields a peak at the $T_{m}$ of the PCR product.

\section{Allele-Specific PCR Amplification}

For analysis of allelic variants, two forward primers were designed, with the $3^{\prime}$ base of each primer matching only one of the biallelic SNP bases to be evaluated. Incorporation of a primer mismatch at the third base from the $3^{\prime}$ end of the primer has been shown to enhance the specificity of the PCR by further destabilizing the extension of the doubly mismatched primer. To additionally distinguish the allelic primers during amplification, different mismatches in the third $3^{\prime}$ base of both forward primers were employed (24). A common reverse primer was designed downstream of the polymorphic site. Primers having a calculated $\mathrm{T}_{\mathrm{m}}$ of $55^{\circ} \mathrm{C}-60^{\circ} \mathrm{C}$ (excluding $\mathrm{GC}$ clamp) were selected.

\section{SYBR Green Fluorescence Melting Curve Analysis}

Genomic DNA (15-40 ng) was amplified in each reaction, using a commercially available SYBR Green master mixture. The master mixture contains a heat-activated Taq DNA polymerase, dNTPs, buffer, and SYBR Green, plus a reference dye. SYBR Green intercalates into dsDNA and fluoresces at excitation/emission wavelengths of $488 / 560 \mathrm{~nm}$. SYBR Green in the PCR master mixture binds to the minor groove of dsDNA, producing up to a 1000-fold increase in fluorescence. As the temperature is raised through the melting point, the DNA denatures and becomes single stranded. This causes a drop in SYBR Green fluorescence. The maximum rate of fluorescence change occurs at the $T_{m}$ of the PCR product.

Primer Express version 2.0 (Applied Biosystems) was used to design the PCR primers. The Sequence Quickie-Calc ${ }^{\mathrm{TM}}$ (Molecular Programming LLC; http:// www.molecularprogramming.com) com- puter program was used to analyze product $\mathrm{T}_{\mathrm{m}} \mathrm{s}$ (Table 1). Products were designed to be in the 50- to $150-\mathrm{bp}$ range as recommended for optimal SYBR Green fluorescence melting curve analysis. By calculation, $50-150$ bp having a $50 \%$ GC content produce products with $\mathrm{T}_{\mathrm{m}} \mathrm{s}$ ranging from $65^{\circ} \mathrm{C}$ to $80^{\circ} \mathrm{C}$. In these products, a single base change often does not affect the $T_{m}$ sufficiently to resolve SNP alleles. To increase the differences in the $\mathrm{T}_{\mathrm{m}} \mathrm{s}$ between different alleles, a random GC segment was added to the $5^{\prime}$ end of one of the specific forward primers. The GC clamp was added to the primer of the product with the highest initial $\mathrm{T}_{\mathrm{m}}$ to achieve a difference of $4^{\circ} \mathrm{C}$ or more between the two alleles. Although computer analysis gives an indication of performance of the assay, it is probably not absolutely required, as the addition of any 10- to 15-bp GC clamp is likely to sufficiently change the $\mathrm{T}_{\mathrm{m}}$ of products in this range.

\section{Genotyping}

Forward and reverse primers were titrated over a range of $50-900 \mathrm{nM}$. Allele-specific reactions were analyzed with individual forward and reverse primer sets. The minimum concentration of primer yielding consistent amplification and melting curves was determined. For single-tube genotyping, forward primers for each allele, plus the common reverse primer, were combined. Amplification conditions consisted of a $10-$ min preincubation at $95^{\circ} \mathrm{C}$ to activate the Taq DNA polymerase, followed by 40 cycles of denaturation at $95^{\circ} \mathrm{C}$ for $15 \mathrm{~s}$ and then primer annealing and extension for $1 \mathrm{~min}$ at $60^{\circ} \mathrm{C}$. The fluorescence melting curve was analyzed immediately following amplification. The GC clamp genotyping method was evaluated using 100 control DNA samples. Informed consent was obtained in accordance with the policies of the Institutional Review Board, OSU.

\section{RESULTS}

\section{ApoE 112}

The ApoE 112 locus is typically difficult to amplify. This DNA region has a GC content of $70 \%-75 \%$, causing 
Short Technical Report

Table 1. Primer Sequences, PCR Product Length, GC Content, and $T_{m} s$

\begin{tabular}{|c|c|c|c|c|c|}
\hline Allele & $\begin{array}{l}\text { Forward Primer } \\
\qquad\left(5^{\prime} \rightarrow 3^{\prime}\right)\end{array}$ & $\begin{array}{l}\text { Reverse Primer } \\
\qquad\left(5^{\prime} \rightarrow 3^{\prime}\right)\end{array}$ & $\begin{array}{l}\text { Product } \\
\text { Length (bp) }\end{array}$ & $\begin{array}{l}\% \\
\text { GC }\end{array}$ & $\begin{array}{c}\text { Product } \mathrm{T}_{\mathrm{m}} \\
\text { (predicted) }\left({ }^{\circ} \mathrm{C}\right)\end{array}$ \\
\hline $\begin{array}{l}\text { ApoE } 112 \\
\text { Cys }\end{array}$ & GCGGACATGGAGGACGaGT & GGTGCTCTGGCCGAGCAT & 75 & 72 & 85 \\
\hline $\begin{array}{l}\text { ApoE } 112 \\
\text { Arg }\end{array}$ & $\frac{\text { CGCGGCCGGCCGCGGACAT }}{\text { GGAGGACGCGC }}$ & GGTGCTCTGGCCGAGCAT & 86 & & 89 \\
\hline $\begin{array}{l}A B C A 1 \\
219 \mathrm{~K}\end{array}$ & CTGAGCTTTGTGGCCTACCtAA & GGATGTCCATGTTGGAACGAA & 72 & 52 & 76 \\
\hline $\begin{array}{l}A B C A 1 \\
\mathrm{R} 219\end{array}$ & $\begin{array}{l}\text { CGCGCCGGCCGCGGGAGCT } \\
\text { TTGTGGCCTACCCAG }\end{array}$ & GGATGTCCATGTTGGAACGAA & 84 & & 81 \\
\hline
\end{tabular}

high local $\mathrm{T}_{\mathrm{m}} \mathrm{s}$ and increased secondary structure. Table 1 shows primer pairs and PCR product information. The projected $\mathrm{T}_{\mathrm{m}}$ of the native 75-bp ApoE 112 Cys product is $85^{\circ} \mathrm{C}$. Adding an 11-bp GC clamp to the ApoE $112 \mathrm{Arg}$ allele raises the calculated $\mathrm{T}_{\mathrm{m}}$ to $89^{\circ} \mathrm{C}$. Both ApoE 112 primer sets required $900 \mathrm{nM}$ for optimum amplification. This is the highest primer concentration required by any of our allele-specific assays. After establishing individual primer requirements, the primer sets were combined, using a final concentration of $900 \mathrm{nM}$ for all three primers. Melting curves of the two allelic products were the same whether used in separate reactions or combined and were easily distinguishable (Figure 1). The $\mathrm{T}_{\mathrm{m}}$ of the ApoE 112 Cys product in 98 analyzable samples was $87.59^{\circ} \mathrm{C} \pm 0.34^{\circ} \mathrm{C}$. The $\mathrm{T}_{\mathrm{m}}$ of the GC-clamped ApoE $112 \mathrm{Arg}$ product was $90.18^{\circ} \mathrm{C} \pm 0.36^{\circ} \mathrm{C}$, clearly separating the two alleles. The observed product $T_{m}$ s were quite consistent, but higher than the predicted $\mathrm{T}_{\mathrm{m}}$. This may be due to the effect of secondary structure or stabilization by SYBR Green binding. These effects cannot be calculated by either of the two programs used to estimate the $T_{m} s$.

Genotype results were confirmed for all 100 samples using specific $A p o E$ 112 Cys/Arg TaqMan MGB allele discrimination probes (forward primer, 5'-CTGTCCAAGGAGCTGCAGG-3'; reverse primer, 5'-TCGCCGCGGTACTGCA-3'; Cys probe, 5'-AGGACGTGtGCGGC-3'; Arg probe, 5'-TGGAGGACGTGCGC-3'). Of 100 samples, two failed to amplify under either con- dition. The TaqMan assay required repetition of two samples, the GC clamp allele-specific assay required repeats of two different samples to obtain unambiguous results. The final result was a $98 \%$ success rate for both assays, with $100 \%$ agreement of genotyping calls. In this sample population, the $A p o E$ 112 Cys frequency was $85 \%$. The ApoE 112 Arg frequency was $15 \%$.

\section{ABCA1 R219K}

The $A B C A 1 \mathrm{R} 219 \mathrm{~K}$ product has a
GC content of $52 \%$, with a projected $\mathrm{T}_{\mathrm{m}}$ of $76^{\circ} \mathrm{C}$. A 15 -bp GC clamp was added to the normal (R219) allele, giving a projected $\mathrm{T}_{\mathrm{m}}$ of $81^{\circ} \mathrm{C}$. Each $A B C A 1$ R219K allele-specific primer set amplified consistently well at forward and reverse primer concentrations of $400 \mathrm{nM}$. When the three primers were combined, a 400-nM R219 forward and reverse primer concentration and 300-nM 219K forward primer concentration provided equivalent amplification of alleles in heterozygous samples. In 98 amplifiable samples, the $\mathrm{T}_{\mathrm{m}}$ of the R219 allele

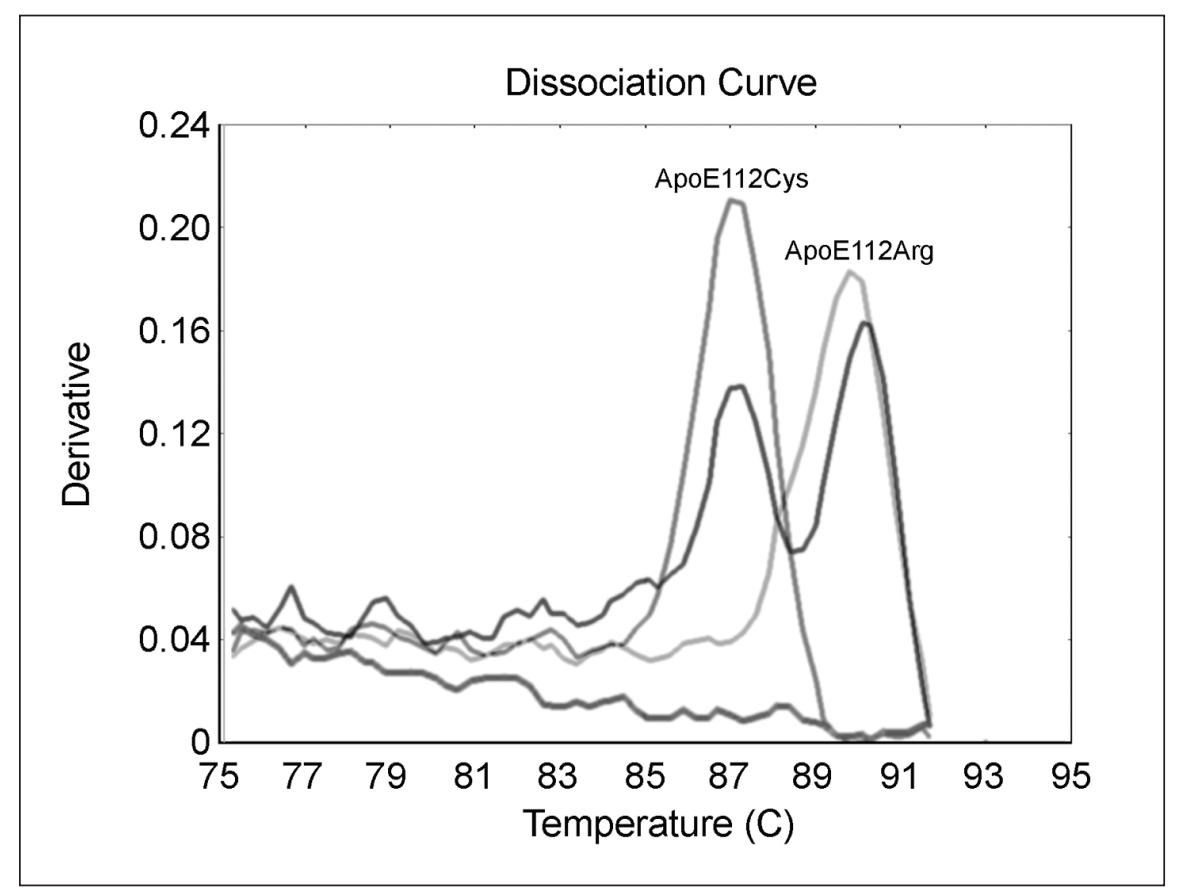

Figure 1. ApoE $112 \mathrm{~T}_{\mathrm{m}}$ curves. Cys homozygote peak is at $87^{\circ} \mathrm{C}, \mathrm{Arg}$ homozygote peak is at $90^{\circ} \mathrm{C}$, and heterozygote includes both peaks. No template control is at bottom. 
was $84.83^{\circ} \mathrm{C} \pm 0.23^{\circ} \mathrm{C}$. The $\mathrm{T}_{\mathrm{m}}$ of the $219 \mathrm{~K}$ allele was $79.38^{\circ} \mathrm{C} \pm 0.30^{\circ} \mathrm{C}$. The same two samples failed to amplify, as in the $A p o E$ assay above. The frequencies of the Arg and Lys alleles were $75 \%$ and $25 \%$, respectively. Figure 2 shows fluorescence melting curves of a 96-well plate.

For validation of the melting assay of $\mathrm{R} 219 \mathrm{~K}$, nine samples were selected: three samples homozygous for R219, three samples homozygous for $219 \mathrm{~K}$, and three heterozygous samples, as identified by melting curve analysis. The $A B C A 1 \mathrm{~K}$ variant creates an EcoNI restriction enzyme site. The selected samples were amplified with a forward primer located 116 bases $5^{\prime}$ of the polymorphism $\left(5^{\prime}\right.$-CTTCCAGGTATTTTTGCAAGGC-3'). The EcoNI digestion results were in complete agreement with the predicted genotypes (data not shown).

\section{DISCUSSION}

The majority of genotyping methods such as restriction enzyme digestion, hybridizations, physical separations, and sequencing rely on PCR amplification, followed by additional identifica- tion and resolution steps. Techniques combining amplification and detection have been developed but require either expensive probes or individual reactions for each allele. The goal of this project was to combine several techniques for analyzing both alleles in the same reaction and, in real time, using SYBR Green with no need for additional steps. In the method presented here, two key components are used enhance PCR genotyping. First, allelespecific amplification with the additional 3' mismatch enhances discrimination between the two alleles. The difference in hybridization temperature of a primer with two mismatches is probably insufficient to differentially amplify two alleles. In this assay, specificity is provided by the inefficient extension of the Taq DNA polymerase from a primer having an unmatched 3' end. The allele-specific primers can be designed either in their forward or reverse direction; however, the primer orientation should be the same (forward or reverse) if both reactions are performed in the same tube. Second, the addition of the GC clamp makes this method universally applicablethe $T_{m}$ of one allele can be adjusted as necessary to give distinct separation of

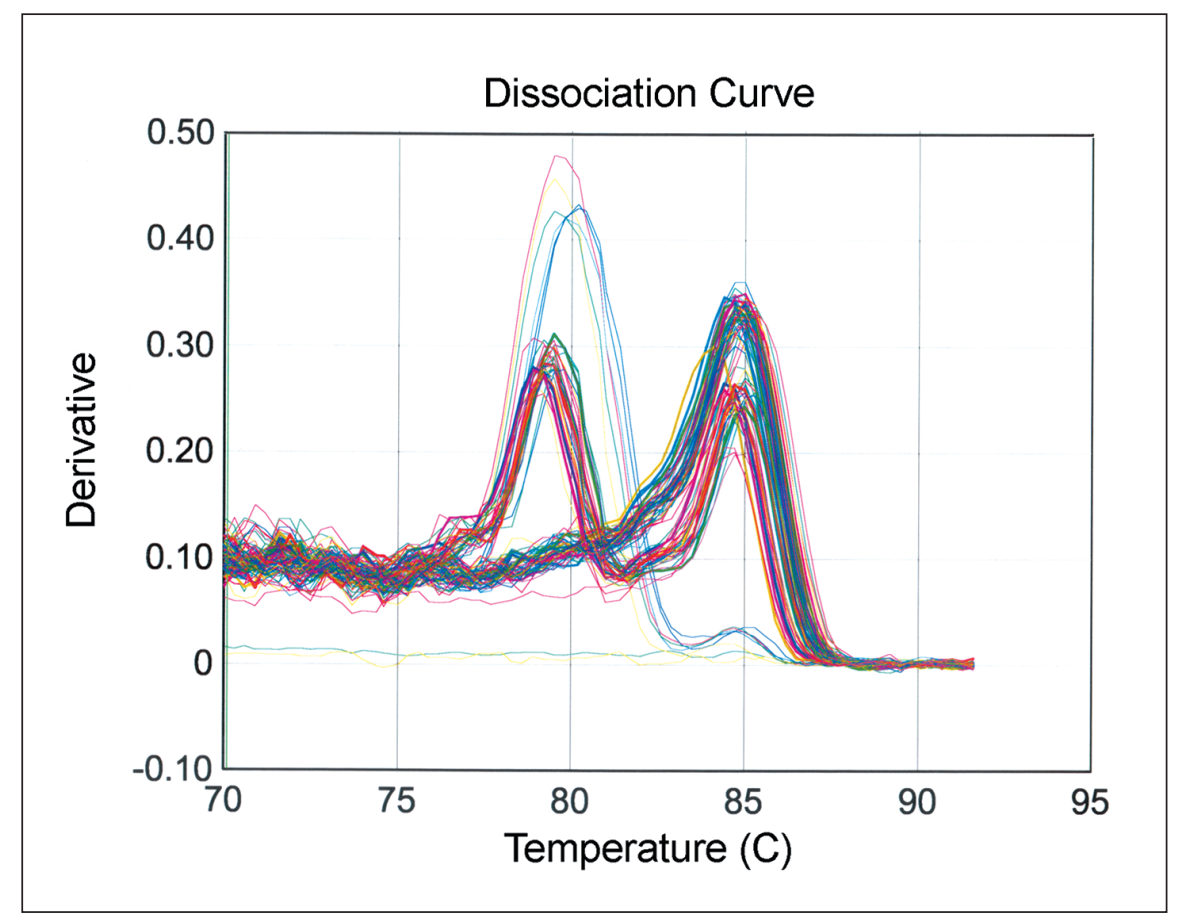

Figure 2. ABCA1 R219K analysis in a 96-well plate. Melting curves for 88 samples and controls. 
melting curves. $\mathrm{T}_{\mathrm{m}}$ analysis has been extensively used for many mutation detection techniques. Nevertheless, using conventional PCR amplification, a single base change may not give a readily discernible difference in $\mathrm{T}_{\mathrm{m}}$, without using additional specialized equipment. The GC clamp works well for samples over a range of GC content and melting temperatures. Addition of the GC-rich sequence to the $5^{\prime}$ end of the primer does not interfere with its annealing to the original sequence. The examples presented have a $20 \%$ difference in GC content of native sequence. Exploiting both allele-specific PCR and GC clamp/differential melting analysis generates a robust SNP genotyping method broadly applicable to current instrumentation.

The GC clamp allele-specific assay is reliable, inexpensive, and simple to perform. Addition of a GC clamp to an allele-specific PCR primer ensures a readily measurable difference in the $T_{m}$ of two alleles amplified in the same reaction. Primers are standard DNA oligonucleotides, and there is no need for additional fluorescent probes other than the generic SYBR Green fluorescent dye. All reactions and measurements take place in a single closed tube, eliminating manipulation of PCR product and removing the risk of postPCR contamination. PCR product is detected by SYBR Green fluorescence in vitro, using an integrated fluorometer-thermal cycler such as the Applied Biosystems 7000 Series or any other instrument. Results are obtained immediately after PCR, without the need for electrophoresis or restriction enzyme digestion. Depending on the instrument, the PCR and fluorescence melting point analysis can be performed in capillaries, tubes, and 96- or 384-well plates. The process uses endpoint analysis of PCR product so that realtime monitoring of $\mathrm{PCR}$ progression or cycle threshold is not necessary. Performing PCR in separate thermal cyclers and then evaluating the fluorescence melting curve of the product in a dedicated instrument could further increase throughput. This method should be particularly useful for the mediumto high-volume laboratory desiring a cost-effective technique for rapid DNA polymorphism analysis.

\section{ACKNOWLEDGMENT}

This work was in part supported by a grant from the National Institutes of Health, General Medical Sciences, GM61390 to W.S.

\section{REFERENCES}

1.Guttmacher, A.E. and F.S. Collins. 2002. Genomic medicine - a primer. N. Engl. J. Med. 347:1512-1520.

2.Phillips, K.A., D.L. Veenstra, E. Oren, J.K. Lee, and W. Sadee. 2001. Potential role of pharmacogenomics in reducing adverse drug reactions: a systematic review. JAMA 286 . 2270-2279

3.Sachidanandam, R., D. Weissman, S.C. Schmidt, J.M. Kakol, L.D. Stein, G. Marth, S. Sherry, J.C. Mullikin, et al. 2001. A map of human sequence variation containing 1.42 million single nucleotide polymorphisms. Nature 409:928-933.

4.Venter, J.C., M.D. Adams, E.W. Myers, P.W. Li, R.J. Mural, G.G. Sutton, H.O. Smith, M. Yandell, et al. 2001. The sequence of the human genome. Science 291:1304-1351.

5.Saiki, R.K., C.A. Chang, C.H. Levenson, T.C. Warren, C.D. Boehm, H.H. Kazazian Jr., and H.A. Erlich. 1988. Diagnosis of sickle cell anemia and $\beta$ thalassemia with enzymatically amplified DNA and nonradioactive allelespecific oligonucleotide probes. N. Engl. J. Med. 319:537-541.

6.Tyagi, S. and F.R. Kramer. 1996. Molecular beacons: probes that fluoresce upon hybridization. Nat. Biotechnol. 14:303-308.

7.Orita, M., H. Iwahana, H. Kanazawa, K. Hayashi, and T. Sekiya. 1989. Detection of polymorphisms of human DNA by gel electrophoresis as single-strand conformation polymorphisms. Proc. Natl. Acad. Sci. USA 86:2766-70.

8.Prior, T.W., A.C. Papp, P.J. Snyder, A.H. Burghes, M.S. Sedra, L.M. Western, C. Bartollo, and J.R. Mendell. 1993. Identification of two point mutations and a one base deletion in exon 19 of the dystrophin gene by heteroduplex formation. Hum. Mol. Genet. 2:311-313.

9.Liu, W., D.I. Smith, K.J. Rechtzigel, S.N. Thibodeau, and C.D. James. 1998. Denaturing high performance liquid chromatography (DHPLC) used in the detection of germline and somatic mutations. Nucleic Acids Res. 26:1396-1400.

10.Newton, C.R., A. Graham, L.E. Heptinstall, S.J. Powell, C. Summers, N. Kalsheker, J.C. Smith, and A.F. Markham. 1989. Analysis of any point mutation in DNA. The amplification refractory mutation system (ARMS). Nucleic Acids Res. 17:2503-2516.

11.Sanger, F., S. Nicklen, and A.R. Coulson. 1977. DNA sequencing with chain terminating inhibitors. Proc. Natl. Acad. Sci. USA 74:5463-5467.

12.Syvanen, A.C., K Aalto-Setala, K. Kontula, and H. Soderlund. 1990. A primer guided nucleotide incorporation assay in the genotyping of apolipoprotein E. Genomics 8:684-692.

13.Livak, K.J., S.J.A. Flood, and J.A. Todd.
1995. Towards fully automated genome-wide polymorphism screening. Nat. Genet. 9:341342.

14.Ririe, K.M., R.P. Rasmussen, and C.T. Wittwer. 1997. Product differentiation by analysis of DNA melting curves during the polymerase chain reaction. Anal. Biochem. 245:154-160.

15.Sarkar, G., J. Cassady, C.D.K. Bottema, and S.S. Sommer. 1990. Characterization of polymerase chain reaction amplification of specific alleles. Anal. Biochem. 186:64-68.

16.Newton, C.R., A. Graham, L.E. Heptinstall, S.J. Powell, C. Summers, J.C. Kalsheker, and A.F. Markham. 1989. Analysis of any point mutation in DNA: the amplification refractory mutation system (ARMS). Nucleic Acids Res. 17:2503-2516.

17.Sheffield, V.C., D.R. Cox, L.S. Lerman, and R.M. Myers. 1989. Attachment of a 40 base pair $\mathrm{G}+\mathrm{C}$ rich sequence ( $\mathrm{GC}$ clamp) to genomic DNA fragments by the polymerase chain reaction results in improved detection of single-base changes. Proc. Natl. Acad. Sci. USA 86:232-236.

18.Mahley, R.W. and Y. Huang. 1999. Apoliprotein protein E: from atherosclerosis to Alzheimer's disease and beyond. Curr. Opin. Lipidol. 10:207-217

19.Rall, S.C., Jr., K.H. Weisgraber, and R.W Mahley. 1982. Human apolipoprotein E: the complete amino acid sequence. J. Biol. Chem. 257:4171-4178.

20.Fullerton, S.M., A.G. Clark, K.M. Weiss, D.A. Nickerson, S.L. Taylor, J.H. Stengard, V. Salomaa, S.E. Vartiainen, et al. 2000 Apolipoprotein $\mathrm{E}$ variation at the sequence haplotype level: implications for the origin and maintenance of a major human polymorphism. Am. J. Hum. Genet. 67:881-900.

21.Oram, J.F. and A.M. Vaughan. 2000 ABCA1-mediated transport of cellular cholesterol and phospholipids to HDL apolipoproteins. Curr. Opin. Lipidol. 11:253-260.

22.Clee, S.M., A.H. Zwinderman, J.C. Engert, K.Y. Zwarts, H.O. Molhuizen, K. Roomp, J.W. Jukema, V, van Wijland, et al. 2001. Common genetic variation in ABCA1 is associated with altered lipoprotein levels and a modified risk for coronary artery disease. Circulation. 103:1198-1205.

23.Wang, J.W., J.R. Burnett, S. Near, K. Young, B. Zinman, A.J.G. Hanley, P.W. Connelly, S.B. Harris, and R.A. Hegele. 2000. Common and rare ABCA1 variants affecting plasma HDL cholesterol. Arterioscler. Thromb. Vasc. Biol. 20:1983-1989.

24.Okimoto, R. and J.B. Dodgson. 1996. Im proved PCR amplification of multiple specific alleles (PAMSA) using internally mismatched primers. BioTechniques 21:20-26.

Received 10 February 2003; accepted 10 March 2003.

Address correspondence to:

Audrey C. Papp

Department of Pharmacology

5068 Graves Hall, 333 W. 10th Avenue

Ohio State University

Columbus, $\mathrm{OH} 43210$, USA

e-mail:papp.2@osu.edu 